\title{
DEVELOPMENT IN REMOTE REGIONS: WHAT DO WE KNOW?
}

\author{
by \\ Lee Huskey, Professor of Economics \\ Department of Economics \\ and \\ Thomas A. Morehouse, Professor of Political Science \\ Institute of Social and Economic Research \\ School of Public Affairs, University of Alaska Anchorage \\ 3211 Providence Drive \\ Anchorage, Alaska 99508
}

July 1991 


\title{
DEVELOPMENT IN REMOTE REGIONS: WHAT DO WE KNOW?
}

\author{
by \\ Lee Huskey, Professor of Economics \\ Department of Economics \\ and \\ Thomas A. Morehouse, Professor of Political Science \\ Institute of Social and Economic Research \\ School of Public Affairs, University of Alaska Anchorage \\ 3211 Providence Drive \\ Anchorage, Alaska 99508
}

July 1991

This mblication is printed on recycled paper. 


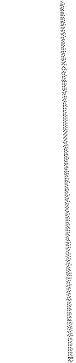




\section{ABSTRACT}

This article assesses a recent body of research on economic development and socio-political change in northern and other remote regions of developed, western nations. The regions include northern Canada, Alaska, northern Scandanavia, Australia's Northern Territory, and Micronesia. Research topics covered are theoretical perspectives, resource development, Native claims, and village economies. "Remote regions" are physically, economically, and politically distant from centers of wealth and power; they are culturally or ethnically diverse and sparsely settled; and they exhibit extreme limits on their autonomy, self-sufficiency, and welfare. "Development" of these regions is defined as the overcoming of internal and external obstacles to change in conditions associated with their remoteness. The authors ask whether the research has increased our understanding of the nature of these regions and of their development problems. Their answer is generally affirmative, but they also identify specific research gaps, problems, and needs. The latter include needs for more explicit theorizing, comparative and historical approaches, and research on resource ownership. Native claims outcomes, village subsistence, and population migration.

Key words: Canada, Alaska, remote regions, development, resources, Native claims, village economies 


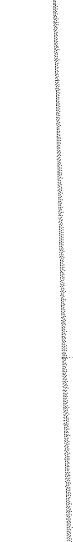




\section{INTRODUCTION}

The Northern Development/Remote Regions sessions of the annual meetings of the Western Regional Science Association (WRSA) have, since 1984, provided an international forum for the exchange of information and ideas among social scientists with research interests in the development processes and problems of northern and other remote regions.

Participants in these sessions have included economists, political scientists, historians, anthropologists, sociologists, geographers, and planners. Most are based in universities in Canada and Alaska, but there have also been participants from Australia, Scandanavia, Micronesia, and the conterminous United States. In general, these researchers specialize in historical and contemporary development problems of their regions, and most focus on northern North America. The research covers a wide range of remote places and problems from a variety of academic and applied viewpoints. In most cases the regions are within developed, democratic states, and they are geographically distant from metropolitan centers, sparsely settled, and culturally or ethnically diverse.

In this article we assess what the research presented in the WRSA sessions has told us about northern and other remote regions, and we suggest directions for future research. This review focuses on approximately 50 of the 150 papers contributed to the sessions from 1984 through 1990. We did not attempt to select "representative" papers; instead, we chose papers that made significant statements about the themes, problems, and methodologies reported in the sessions over the seven year period. The papers deal with the following broadly defined topics, which constitute the four parts of this article: theoretical perspectives, resource development, Native claims, and village economies. 
This review discusses the papers' main concepts and definitions, theoretical frameworks, problem and policy orientations, and findings and conclusions. We ask two questions about the research: First, has it helped us to better understand how and why remote regions are different from other places? Second, has it given us a clearer view of remote regions' problems and what might be done about them?

While this review focuses on papers presented in the WRSA remote regions sessions, we refer to a few selected works outside the sessions in order to relate the research to relevant literature on economic and political development and sociocultural change. (The authors of this article have been the organizers of the WRSA remote regions sessions as well as participants in them.)

\section{THEORETICAL PERSPECTIVES}

Although we lack theories specifically for the study of remote regions and their development, the research has not been devoid of theories or theorizing. Some of the papers refer explicitly to theoretical frameworks, and the papers collectively incorporate a variety of analytical and normative perspectives, assumptions, and purposes. This part of the discussion examines the concepts of remoteness and development and the influence of certain social science theories on the research.

\section{Remoteness and Development}

What have we meant by "remote regions" and their "development"? Most of the regions we have studied are remote geographically, economically, and politically. They are distant from large, urban industrial and political centers, and they are sparsely settled. Most of them contain Native or indigenous populations as well as non-Native immigrants, and they have a mix of traditional and western institutions. Typically, they have limited market economies, and 
they are dependent on natural resource exports, government transfers, and subsistence activities. The costs of doing public and private business are high. Important decisions affecting these areas are made in distant metropolitan centers. These remote regions lack both political autonomy and economic self-sufficiency.

A significant implication of these characteristics is that most of the researchers view remote regions as problem areas suffering from a complex set of physical, economic, and political limits on their security, welfare, and autonomy.

Development, in this view, is a process of overcoming obstacles to desired forms of change. Different, often conflicting objectives for social, economic, and political change are sought by organized interests within and outside the region. Indigenous groups, for example, may give priority to renewable resource and subsistence values, while immigrants to the region may focus on the production and export of non-renewable resources. In such a context, the term "development" is often used to refer only to the interests of immigrant groups, but this is too narrow a use of the term. Indigenous groups seek changes in disadvantageous economic and political conditions. In this sense, indigenous groups also seek "development," particularly the kind of development that would give them greater control over their economic and political fortunes.

\section{Modernization, Dependency, and Interdependence}

"Development" as the overcoming of obstacles is associated with the "modernization" school in the development literature (Staniland, 1985; So, 1990). Emerging in the 1950s, this school saw modernization of Third World countries as "a phased, irreversible, progressive, lengthy process that moves in the direction of the American model" (So, 1990:261). Modernity in this model is set against and expected to overcome the obstacles particularly of indigenous traditions. 
A contrasting meaning of development came out of the "dependency" school, which arose in the 1960 s in part as a reaction to the failures of modernization in theory and practice (Staniland, 1985:121-123, So, 1990: 91-93). This school "conceptualized the linkages between Western and Third World countries as a set of externally imposed, exploitative, dependent economic relationships incompatible with development" (So, 1990:262). In the view of dependency theorists, development controlled by Western capitalists leads inevitably to systematic "underdevelopment" of Third World regions.

The modernization school emphasizes overcoming internal obstacles to development. These obstacles are associated with traditionalism and the conditions of remoteness discussed above. On the other hand, the dependency school and its relative, "world-system" theory (Wallerstein, 1974, 1979), focus on external forces of capitalism. These forces are viewed as suppressing indigenous peoples, destroying their traditions, and expropriating their property.

A third, less definite perspective arose in the 1970 s and 1980 s, and it has been labeled the "interdependence" school (Staniland, 1985:110-117). This school compensates for the one-sidedness of the modernization and dependency schools by focusing on complex interdependencies of internal and external factors. It also emphasizes the use of countervailing political power to shape economic relationships. Core-capitalist domination of peripheral Third World economies is not taken for granted.

The modernization and dependency schools have been converging, although neither of them has lost its distinctive focus. These schools increasingly share a concern for "historically specific concrete cases" and for "multi-institutional analysis" that focuses on the complex interplay of "family, religion, ethnic groups, classes, the interstate system, and the world-economy" in Third World countries (So, 1990:267). In current research, the question of whether development is considered good or bad for indigenous peoples is left open, with 
the answer presumably depending more on the outcomes than on the theoretical assumptions of the analysis.

\section{Third World and First World}

Theoretical perspectives on problems of Third World development have had an important influence on the remote regions research reviewed here. This, despite the fact that the remote regions of primary concern are not Third World countries. The research has dealt only incidently with "developing" states and regions in Africa, Asia, and Latin America. The focus instead has been on remote regions within highly developed, liberal democratic states: Alaska in the United States, northern Canada, Australia's Northern Territory, northern Scandanavia, and Micronesian states and territories controlled by the United States. (Two papers have dealt with the Soviet Far Northeast.)

The boundaries of these remote regions are extremely permeable. They are open economically, politically, and culturally. There is great mobility of people, capital, and goods between these regions and their encompassing states. These regions are relatively simple parts of large, complex nation-states that have elaborate constitutional-legal systems, rich economies, and overarching, dominant cultures.

The main implication of this contextual dimension is that there are established national systems of economic and political opportunities and limits, and cultural constraints, within which these remote regions function. It thus seems important that we inquire into how these particular systems affect developments and choices within the specific focuses of our research. We clearly are not dealing with the types of "nation-building" and international relationships associated with Third World cases.

Instead of dealing with international relations, imperialism, or nation-building, we are studying relationships between central governments and the territories, provinces, states, 
other sub-national units, and the populations within them. Drawing parallels between the Third World and our remote regions can suggest general lines of research, but these are not substitutes for a focus on the "First World" relationships that are directly at issue.

Important similarities and differences exist among nation states in their relationships with their remote regions, and we seem to learn more about these relationships when we view them within a comparative framework. Relationships of domination and cooperation vary significantly, for example, between a culturally integrated and socially-oriented Sweden, on the one hand, and a more fragmented and individualistic Australia, on the other.

\section{Problems and Disciplinary Perspectives}

Remote regions research has focused on two problem areas. The first is the problem of economic development. This problem has been addressed primarily by economists, who generally define it as one of overcoming internal obstacles to achieving the sustainability or merely the growth of remote economies. This definition reflects a modernization perspective. It emphasizes internal, inhibiting factors such as geographical isolation, small populations and markets, high costs, and dependence on natural resource exports (Watkins, 1972; Leven, 1986).

The economists' focus is not exclusively on internal factors, however. They have also indicated the significance of the openness of remote region economies: the flows of capital, transfers, people, and goods, which have both positive and negative effects on these economies, and which limit what regional interests can do about local economic conditions. Although several remote regions researchers have included both internal and external levels of economic factors in their analyses, few have attempted systematic application of explicit theoretical frameworks. Two who have are Huskey (1987), who contrasted the "frontier" development experiences of Alaska and the American West, and Berman (1987), who 
analyzed economic and political responses to factors inhibiting economic development in northern regions.

The second major problem area addressed by the remote regions research has been that of reconciling political autonomy and cultural identity with economic development. The authors of papers falling into this category are mainly anthropologists, sociologists, political scientists, and historians. One of the more theoretical of these papers, for example, concluded that there is a direct conflict between political autonomy and economic development (Nord, 1990). A few others have also taken a broad approach, discussing problems of transferring power to indigenous peoples, maintaining ethnic identities, and integrating traditional, transfer, and market economies (Berman, 1986; Dubbs, 1988; Morehouse, 1986, 1989; Lyck, 1990). Most remote regions papers, however, have focused on more limited cases of conflict between traditional and modern cultures. Generally, the emphasis has been on how various external forces--religious, bureaucratic, political, and economic--have suppressed, damaged, or destroyed various aspects of indigenous cultures (e.g., Ballendorf, 1990). These papers tend to reflect the influence of the dependency school, but only two papers attempted to apply dependency theory systematically. One found it useful for a very general interpretation of the "underdevelopment" of the Canadian north (Pretes, 1988). The other demonstrated the inadequacy of the theory when applied to the case of economic development in Canada's Atlantic provinces (Sager, 1988).

Another group of papers has focused on the adaptive capacities of indigenous cultures (e.g., Lonner, 1985; Petterson, 1984; Harris, 1984). Several of them have also proposed policy prescriptions to strengthen indigenous institutions in areas of health (Weller, 1990), subsistence resource management (Osherenko, 1988), rural economic development programs (Coates, 1987), and village economies (Dubbs, 1988). These papers, by examining and proposing various accommodations between internal and external interests, reflect aspects 
of the interdependence or interactive revision of the modernization and dependency perspectives.

Regardless of their disciplinary or theoretical orientations, virtually all of the remote regions papers are concerned with significant economic, political, and sociocultural problems. Some of the papers also offer prescriptions for increasing economic self-sufficiency and political autonomy. One recurring set of proposals is to transfer to indigenous groups greater property rights to lands and natural resources. Questions about the political feasibility of such prescriptions have mostly been ignored, however.

\section{Cenclusion}

Remote regions researchers have generally recognized the interdependencies or interactions of internal and external factors in regional development. Some authors have focused on such interactions, but only a few papers reflect the kind of multi-level, multi-institutional analyses referred to earlier. The research generally has not sought to establish empirical generalizations explaining processes of development and change in remote regions. Often, these processes are assumed as part of a modernization or dependency perspective. Instead of explaining processes, the research has been primarily concerned with defining and explaining problems, but without necessarily proposing solutions.

\section{RESOURCE DEVELOPMENT}

A primary reason for the expansion of modern economies into remote regions has been the pursuit of resources. Export-oriented resource development continues as an important economic factor in remote regions throughout the world. The remote regions papers have examined determinants of resource development with emphasis on government's role, the 
pattern of settlement associated with resource development, and the question of the sustainability of resource-based economies.

\section{Perspective}

The remote regions research views resource development as primarily an economic process and sees development as limited mainly by internal factors. However, government regulation is also important. Resource production takes place when it is profitable or when the world market price covers the cost of producing and transporting the resource to market. Internal factors that hinder resource production include high production costs and high costs of transportation.

Resource production attracts immigrants to the region. Settlement of production workers may be accompanied by additional economic activity serving the resource workers, supplying inputs to the industry, or processing the resource. The extent of settlement in response to resource development is affected by internal conditions of remoteness. An additional factor affecting settlement is the finite nature of most resource deposits. When resource production ends, outmigration will occur if a new economic base is not developed.

\section{Findings}

Several papers examine the federal role in resource development in the North American north. Governments can affect the pace of resource development in remote regions by controlling access to resources and markets and through tax and subsidy policies which affect profitability of production. Coates (1987) found that while the Canadian federal government did little during the early part of this century to encourage development in the Yukon, its policies did influence the pattern of development. By not granting the Yukon Natives an exclusive trapping preserve, for example, the government preserved external access to the 
region's mineral resources. The federal government did provide support to particular mining projects in the latter part of the century.

Any federal effort to encourage development in remote regions must overcome limits imposed by the economic environment of remoteness. Naske (1987) found this to be the problem in early federal development initiatives in Alaska. Historically, federal effort seems most effective in limiting development. The U.S. government's declaration that gold mining was a non-essential industry during World War II shut down what was a profitable and important industrial sector in Alaska (Cole, 1989).

Comparative studies shed additional light on the role of government in northern development. Knowler (1990) compares a northern region of Sweden to the Yukon Territory, and Knapp $(1987,1990)$ compares the Soviet north to Alaska. While the Swedish and Soviet regions have similar climates and locations, they are more developed than the Yukon and Alaska regions. The differences in development are partially explained by differences in resource deposits or other physical features. However, differences in the role of government in each region are more important.

The Swedish government played a more active role in the initial development of the region's resources, and it is more involved in diversification or replacement of the economic activity lost because of declines in resource production. The particular goals of government for resource and local development in the Soviet Union as well as its peculiar economic system help explain the relatively high level of Soviet northern development. In contrast to the Yukon and Alaska cases, governments' support of resource production in the north in Sweden and the Soviet Union is based on the pursuit of non-economic objectives such as resource independence and sovereignty.

A number of papers examine the settlement accompanying resource production. In the case of Alaska, Tuck (1984) and Huskey (1984) find that structural change is an important 
component of regional economic growth. As the region grows, increasing market size allows introduction of new types of economic activity to serve both the resident population and the resource industry. This activity may or may not take place at the resource site. Instead, central places may develop to provide residences and services for the producers. Saarinen (1989) describes how Sudbury, which began as a northern Ontario resource town, has evolved into an important regional center with a more diversified economy. The growth of service activity and the potential for diversification in northern service centers depends on the scale of resource activity and the communities' location in the national transportation system. Shrimpton and Storey (1989) discuss how production methods can limit settlement effects of resource development in the north. The rapid decline in transportation and communication costs permits resource production workers to commute long distances and allows them more choice of residence. It also reduces the costs and increases the flexibility of resource development. Long distance commuting has contradictory effects on the development of remote regions. While lower costs may increase the level of resource production in these regions, the settlement effects will be smaller because fewer workers will live in the region and fewer local goods will be purchased.

A final resource development issue addressed in the remote regions papers is that of sustainable economic development. An economy based on resource production faces two long term problems. First, resource prices are notoriously cyclical and, second, non-renewable resources by definition have a finite life. These characteristics of resource industries create the boom-bust pattern of economic activity common in remote regions.

Knowler (1989) addresses the role of ownership in the cyclical behavior of resource production in remote regions. Using the Yukon Territory as a case study, he examines effects of absentee ownership. While local control of resources is often an expressed interest of residents in remote areas, Knowler's research suggests that absentee ownership helps to 
reduce the impact of the cyclical nature of resource production on the local economy. He finds that nonwage income (e.g., profits) is more unstable than wage income, and absentee ownership exports this instability to other regions.

Goldsmith (1987) and Pretes and Robinson (1989) suggest that economic rents earned from resource production may be used to stabilize resource-based local economies in the long run. The success of this approach depends on the relative size of the resource rents (economic returns), the ability of local governments to capture these rents, and government's ability to save them. The difficulty of government saving is illustrated by the Alaska case. Goldsmith (1985) finds that much of the recent growth in the Alaska economy resulted from government spending of resource rents and that the pattern of government spending may create an additional problem. If rents are spent during the time resources are produced, this magnifies both the boom and bust parts of the cycle.

\section{Further Research}

There are many determinants of resource production and settlement in remote regions. The papers reviewed here, however, focus on the role of government and suggest that governments seem most effective when they pursue non-economic objectives that justify subsidies required to overcome the limits imposed by remoteness.

Many other questions are not addressed by the resource development papers. The most important have to do with the determinants of resource production in remote regions. Comparative studies of successful and unsuccessful resource projects would provide understanding of the relative importance of the limiting factors associated with remoteness. Research focusing on successes and failures might also help define appropriate roles for governments in remote regions. 
A final issue for further investigation is the role of resource ownership in development. Recognizing that government ownership is an important characteristic of remote region economies, research should examine the effects of differences in ownership (e.g., public, private, and mixed forms) on resource development.

\section{NATIVE CLAIMS}

Remote regions papers focusing on Native claims deal with claims movements, settlement acts or agreements, and settlement implementation and outcomes. The papers discuss economic, political, and cultural contexts of claims movements; claims negotiations and settlement provisions; and consequences of settlements for Native rights and welfare.

\section{Perspective}

Overall, the papers suggest that Native claims movements are reactions to resource development pressures exerted from industrial and political centers outside the region. At stake are lands and resources valued by Natives primarily for subsistence use and by outsiders primarily for development and commercial export. Papers focusing on claims settlements tend to characterize them as externally imposed means of defining, circumscribing, and extinguishing Native rights and making land and resources available primarily to external interests. Consistent with this interpretation, researchers who have assessed post-settlement outcomes tend to be pessimistic about the longer term implications for Native rights and welfare.

In terms of the theoretical perspectives discussed above, several of the papers can be interpreted as suggesting that claims settlements are instruments of modernization imposed on peripheral regions from core areas. In this perspective, settlements can be viewed as parts of broader strategies to overcome the barriers to development that are raised by remoteness 
and tradition. To the extent that they also contribute to socializing and training Natives in western ways, and to moving them into the economic and social mainstream, claims settlements can also be considered as instruments of assimilation.

\section{Findings}

Three papers focus respectively on legal, political, and cultural contexts of claims movements, indicating the constraints these contexts place on Native interests.

Morse (1985) describes the constitutional-legal backgrounds and statuses of indigenous claims in Canada's northern territories, comparing them with the cases of Alaska and Australia. Concerning recognition of Native political rights ("sovereignty"), he notes that the United States has an established legal tradition that dates back to the U.S. Supreme Court led by John Marshall in the early nineteenth century. Only in recent decades has Canada recognized such rights in court opinions and law, including the Constitution Act of 1982. Such rights remain largely undefined, however, and their definition depends on uncertain, long term political processes of negotiation controlled by federal and provincial governments. In Australia, the federal government recognized limited Aboriginal land rights only as late as the mid-1970s, and does not recognize any special Aboriginal political rights.

Abele (1985) also focuses on northern Canadian claims, observing that Native claims movements are not independent of established political and economic institutions and processes, but are instead intimately involved in them. Claims movements affect, and are affected by, the political activities and interests of territorial legislative councils, Native development corporations, and constitutional forums. Further, claims negotiations occur within structures managed by government, and they fall within the scope of constitutional provisions yet to be interpreted by federal and provincial government leaders. Overall, Abele 
implicitly conveys a sense of the ways in which claims processes occur within, and are shaped by, the framework of mainstream, majoritarian politics.

Indigenous claims are also constrained by cultural differences among Native groups whose very identity may be dependent on external forces. Dahl (1988) examines the relationship of claims processes to the formation of ethnic identities in Greenland, northern Canada, and Alaska. Only in Greenland did the Native (Inuit) Greenlanders have a strong ethnic identity that pre-existed their home rule movement and provided the basis for "nation-building." In Canada, on the other hand, ethnic identities were reshaped as if opportunistically in relation to the timing and extent of external pressures in different regions. For example, a distinct Inuvialuit identity emerged in the western arctic only after 1970 as an effect of claims processes in the territories. Finally, Dahl notes that in Alaska the claims movement created an artificial and fragile "Alaska Native" identity, which merely glossed over regional and ethnic divisions that were reasserted after Congress passed the Alaska Native Claims Settlement Act in 1971.

Other papers take broad, comparative views of claims processes and come to similar conclusions about the subordination of indigenous values to external forces.

In Morrison's historical perspective (1987), the federal government's basic objectives for contemporary claims settlements in northern Canada are little different from those reflected in the Indian treaties of the late nineteenth and early twentieth centuries. The government still seeks clear title to land for development, and it offers cash, land, and other benefits to Natives in exchange for the extinguishment of aboriginal rights. While new political demands are being made by Native groups, the positions of federal and provincial governments have changed hardly at all. This continuity is reflected in the provisions of the Western Inuvialuit and James Bay and Northern Quebec settlements. It is also demonstrated by the government's rejection of demands for self-government rights in ongoing negotiations 
with the Indians of the Yukon Territory, the Dene and Metis, and the Inuit of the eastern arctic.

Clark and Coates (1990) assess the land struggles of the Yanomamo of Brazil's Amazon, the James Bay Cree of Quebec, and the Aborigines of Australia's Northern Territory. Despite the many differences between these regions, the authors find similar patterns of conflict. Although governments have enacted various measures to protect them (including a claims settlement in the case of the $\mathrm{Cre \theta}$ ), each of these groups remains under great pressure from external interests. In Brazil, miners and ranchers continue to push the Yanomamo out of their territories and destroy their subsistence environment; in Quebec, huge hydropower projects continue to threaten Cree settlements and subsistence lands; and in Australia, corporate mining interests continue to compete with Aborigines for limited land and scarce resources.

Morehouse (1987) compares claims processes in Alaska and northern Canada within a political development and policymaking framework. He characterizes these processes as episodes within a continuing process of politics and problem solving. In this view, settlements are never entirely "settled," although they do affect the terms under which future claims episodes are played out. While claims movements build the strength and express the political vitality of Native groups, claims settlements are likely to be political setbacks because they extinguish and delimit aboriginal land, subsistence, and political rights.

Two papers respectively examine implementation of the Alaska Native Claims settlement Act of 1971 (ANCSA) and a political episode involving important amendments to the act in the mid-1980s.

Anders and Anders (1984) survey cultural, economic, and political consequences of the corporate form of organization established by ANCSA to administer the lands and funds granted to Alaska Natives. They see a fundamental conflict between the individualism and profit motivations of corporate organizational culture, on the one hand, and the cooperative, 
communal, and kinship values of traditional Native culture, on the other. This value conflict is reinforced when these organizations come under the control of non-Native managers due to the shortage of Natives with managerial experience and skills. Also, because of the economic limits of rural Alaska, many of the corporations face potential bankruptcy and loss of lands. At worst, these corporations could contribute to the destruction of Native culture. Morehouse (1988) discusses the political process and the stakes involved in Congressional amendments to the Alaska claims act in the mid-1980s. While Congress was deliberating on amendments that would extend protections over lands and stock of the Native corporations created by the act, tribal leaders sought amendments that would strengthen the role of tribal governments and give them Congressional recognition. Opposed by federal authorities, Alaska's U.S. Senators, the State of Alaska, non- Native interest groups, and Native leaders of ANCSA corporations, the tribal initiative failed. Morehouse concludes that although the tribal government movement remains viable, tribal leaders need to focus more on specific security and welfare goals, avoiding direct confrontations with powerful opponents of Native political rights.

\section{Further Research}

This review suggests at least two areas of further research beyond the current emphasis on claims movements and settlement acts. One is the broad area of claims implementation and outcome studies. These might focus on specific settlement provisions concerning land, subsistence, money, and self-government. The research should attempt to determine how settlement acts affect Native control of lands and resources, Native government structures, and Native access to mainstream social, economic, and political institutions.

The other area is a specific application of implementation and outcomes research. Claims settlements can be viewed as social experiments in transferring property rights to 
Native groups. Economists in particular might focus on effects of different forms of property rights on welfare and efficiency values, and effects of different types of institutions (e.g., profit and non-profit) on the uses of these rights. Such studies would also provide the basis for suggesting ways of increasing both welfare and efficiency through property rights transfers to Native groups.

\section{VILLAGE ECONOMIES}

Indigenous populations of most remote regions rely on some mix of traditional activity, modern sector jobs, and transfer payments, and remote regions papers examine these mixed economies. The papers describe the economies and their problems, examine responses of indigenous populations to external forces, and recommend policy solutions. The dominant geographic focus of these papers is Alaska and the Canadian north.

\section{Perspective}

The central research focus of the village economies papers is the impact on indigenous populations of the development of economic and political relations with the modern economy. The linkage has a relatively long history, and the papers discuss its evolution. Analyses of consequences focus on the opportunities and constraints associated with this relationship. The papers recognize that something is wrong in the village economies. Village problems are seen as social, exhibiting symptoms such as high rates of suicide and alcoholism, and economic, reflecting the view that most village economies cannot be sustained even at existing levels under current institutions and relationships (Dubbs, 1988; Morehouse, 1989). Policy prescriptions vary, and the researchers' views about the relative importance of internal and external limitations is one reason for the differences. 
Differences in theoretical perspectives account for much of the variation in definitions of the problems and proposals for change. The primary differences concern assumptions about human behavior. Economists bring to the topic their special set of assumptions about individual maximizing behavior. To most economists, behavior can be explained by assuming individuals attempt to maximize their utility and respond to changes in opportunities and constraints; this theoretical framework is applied to individual decision making in both traditional and modern sectors.

The critique of the rational individual behavior assumptions is joined by many disciplines. Petterson (1984), for example, argues that treating subsistence resources as only economic resources ignores the important connection with nature that subsistence harvesting provides for the Native population. He also argues that this framework ignores the importance of cultural and social ties and sharing and cooperative behavior. Not only do these theoretical differences suggest different explanations for behavior, they also lead to different policy objectives and prescriptions.

\section{Findings}

\section{Descriptions of the Mixed Economy}

The current situation in northern mixed economies is the subject of a number of papers. These papers generally focus on a single sector and describe its impact on the village economy. The wide diversity of experiences in northern regions is reflected in these papers. This diversity also limits our ability to generalize from the results. Knapp (1988), for example, describes the variation across regions of rural Alaska.

Langdon (1984) and Harris (1984) describe the commercial fishing sector in Alaska villages. While Native village fisheries are not without their problems, they provide an opportunity for obtaining cash and have limited disruptive effects on the traditional economy. 
In many coastal Alaska villages, fisheries provide the largest source of cash. In addition, commercial fishing adaptations approximate social and cultural patterns associated with subsistence, such as the use of domestic modes of production and the territorial and seasonal aspects of production.

Huskey (1986) and Knapp (1986) discuss the importance of transfers in village economies. Transfers are funds directed to villages by either state or federal governments. Real incomes of villagers are affected by transfers through direct income supplements and reductions in costs of goods and services. The most important source of transfer income may be jobs in local, territorial, state, and federal governments.

Knapp and Huskey (1988) estimate that transfers account for nearly one-half of personal income and two-thirds of the economic base in coastal western Alaska. Transfers in village economies increase their dependence on external political systems. In addition, transfers also have an important population effect and may encourage the growth of villages beyond a level which the available subsistence and market resources can support.

Evolution of the current mixed economies in the Northwest Territories and the Yukon Territory are described by Stabler and Howe (1990) and Coates (1987). The patterns of change are similar in the two regions. The indigenous population responded to the opportunity provided by the fur trade to participate in the market economy. Entry into the fur trade was easy because Natives could transfer their traditional skills to this sector. The indigenous population showed a propensity to make major adjustments to exploit the opportunities provided. These include adopting modern technology, modifying their seasonal cycles, and changing their settlement patterns. One result of these changes was an increased dependence on market products. An additional result was greater pressure on food resources from increased migration into the region, settlement, and the use of dog teams for trapping. In the 
Yukon Territory, Coates suggests that movement into the modern sector through employment in mining may have been limited by discrimination.

Growth of the transfer component of the mixed economy was a response to the collapse of the fur market. The fur trade experience illustrates both the benefits and costs of the interdependence that results from specialization and trade. While access to modern goods and technology may have improved Native welfare, collapse of the fur market left the Native population with limited market opportunities. Further, changes in settlement patterns and the overharvesting of game reduced opportunities to pursue subsistence. Finally, limited education and willingness to move limited Natives' abilities to pursue opportunities elsewhere. The government response to the resulting poverty was to provide social assistance and public jobs.

\section{Response to the Modern Economy}

The modern economy affects village economies in three ways. First, it provides jobs in the transfer sector or in resource production. Second, it results in decreased local control over local resources. Finally, opportunities provided by the modern economy affect population movements in and out of the villages.

In a series of papers, Stabler $(1987,1988,1989)$ examines the response of indigenous residents of the Northwest Territorries to the availability of jobs in the modern economy. He observes that while Native residents of the region participate in the modern economy, a significant proportion also participate in the traditional sector. He suggests that this can be explained by two extreme hypotheses: either Natives hold jobs only to acquire cash to pursue traditional activities, or the traditional sector is only an "employer of last resort" where rural residents wait for jobs. If the second hypothesis is true, limited participation might be explained by discrimination in the modern sector, the lack of job opportunities, or both. 
Data from the Northwest Territories, however, support a more complex explanation: Limited job opportunities establish a queve, and the probability of employment increases with education. With increased education, opportunity to work in the modern sector increases, and people take advantage of the opportunities. The traditional sector provides residents with an opportunity to supplement their income, which is especially important since most jobs in these regions are not full time. Evidence supports the hypothesis that residents of the Northwest Territories exercise choice in making full use of all opportunities, both modern and traditional, for improving their livelihoods.

Resources used for traditional activity and commercial harvesting activity in remote regions are common property or open access resources. The conventional economic argument is that open access results in overharvesting. Although there is evidence that indigenous populations managed the common property problem through communal forms of "ownership" (Usher, 1987), external political control brings other limits on access to resources. Limiting access increases the incomes of those who have access and may cause others to migrate from the region (Copes, 1987).

Berman (1990) argues that limiting entry has costs that are ignored in most economic analyses. The cost is that limiting access to resources limits opportunities, and this may make people worse off. If the mobility of rural residents is low and opportunites for other employment in the region are limited, resource harvesting serves as an important employer of last resort. In coastal Alaska fishing villages, limited entry prevents some residents from using the local resources to meet their cash needs (Langdon, 1984). Berman suggests that allowing leasing of permits or limiting harvests through share quotas would be ways of achieving the efficiency goals of limited access while preserving villagers' options. 
The introduction of the modern economy into villages also affects population movements. Migration is one way that local economies achieve a balance, with migration into and out of the community responding to the availability of opportunities to earn income. Huskey (1989) examines the effect of transfer payments on migration, assuming that such payments keep people in rural regions with limited modern sector opportunities. One effect of this would be increased pressure on open access subsistence resources. An initial empirical test of the hypothesis suggests that while transfers may limit outmigration, the effect is not very strong. Support for a hypothesis of limited mobility among indigenous populations is also provided by experience in Australia. In his study of mobility in the Northern Territory, Taylor (1988) finds that job opportunities specifically available for the Aboriginal population in a regional center had little effect on their migration behavior.

\section{Policy Prescriptions}

A number of papers offer prescriptions for increasing the economic self-sufficiency of remote villages. Although self-sufficiency is not explicitly defined in the papers, they do contain elements of an implicit definition. Self-sufficiency implies that the local economy provides residents with a defined level of real income. Self-sufficiency is also a place-oriented objective, implying villagers should be provided economic opportunities in their villages.

The prescriptions for self-sufficiency are shaped by development constraints. Three types of problems are associated with economic development in Native villages. First, economic limits are imposed by the small size and remoteness of most villages; these limit opportunities for market activity and increase the cost of living. The second set of problems is associated with dependency and control; not only are decisions affecting the local economy made outside the region, there may also be external controls on access to local resources. Third, rapid growth of population in the villages complicates the problem of economic 
development by increasing the required level of economic activity (Stabler, 1990; Langdon, 1984).

Dubbs (1988) and Morehouse (1989) provide the most universal recommendations for these problems. Both recognize that a self-sustaining economy for villages is a mixed economy able to use resources for subsistence and the market. Both authors suggest legal changes to guarantee access to and control of land for subsistence activites. This includes not only Native- owned land, but also state and federal lands required for subsistence.

Several authors advocate changes in state, provincial or territorial, and federal laws that limit use of resources for commercial purposes by Native villagers. Native control and use of non-renewable resources may in some areas provide modern sector jobs and incomes (Sinclair, 1985). Berman (1986) and Langdon (1984) suggest that pursuit of local fish and game for sale is the comparative advantage of many villages.

Another way to increase village income is through Native participation in modern sector jobs. Reporting on a demonstration project in an Alaska village, Lane and Thomas (1984) found that changes in the structure of jobs and wage rates to allow for more on-the-job training, and to account for cultural characteristics such as group cooperation, can increase Native participation in modern sector jobs in the village.

Although he suggests a number of additional ways to increase the level of income in the villages, Dubbs (1988) also recognizes the continued importance of transfer payments. In addition to public transfers, Dubbs sees the possibility of future private transfer from such entities as Alaska's regional Native corporations. Pretes and Robinson (1989) suggest that investment funds modeled on Alaska's Permanent Fund could be established to hold resource rents or settlement payments as a way of creating a sustainable financial resource in northern Canada. 
Policies like those discussed above will increase economic opportunities in villages, but sustainable economies in some regions require substantial transfers. Limited economic opportunities and rapid growth of village populations suggest that policies which encourage, or at least do not discourage, outmigration may be appropriate. Stabler and Howe (1990) suggest that programs designed to assist outmigration may be the only option in the face of unemployment rates approaching 50 per cent.

\section{Further Research}

The current mixed economy of northern villages is the result of a long period of adjustment by the indigenous population to the opportunities offered and constraints imposed by contact with external political and economic forces. Natives have responded to opportunities to earn income and have made significant adjustments in their way of life. The contemporary village resident takes advantage of opportunities offered by both traditional and modern economies to create a livelihood. Economic problems of villages seem to be the result of limits to opportunities resulting from both the economic environment and limited access to local resources imposed by external control. Solutions have focused on the limits imposed by external control, but have given little attention to changing the regional economic environment.

This review suggests several topics for further research. One is the role of subsistence in village economies. There is great variety in subsistence patterns among regions and villages. Research should examine the variation in subsistence activity in response to the richness of the resource, the availability of alternative sources of income, and other factors that might be hypothesized as affecting subsistence activity.

A second research need is to test policy prescriptions. Case studies of villages that have gained increased control of resources would help us understand the effects of this political 
change. Related research would investigate population levels that might be sustained through existing government transfers, existing employment opportunities, and increased access to a region's resources. This would also shed light on effects of local control of resources and on the level of transfers and job opportunities required to sustain the population at a given level.

A third policy-related research topic is migration. The relative mobility of villagers should influence policy choices. The less mobile villagers are, the more important place-oriented policies become. Comparative studies of remote regions might reveal the relative roles of culture and policy in determining the mobility of village populations. Comparing village population movements over time may show how economic opportunities affect migration. Finally, outmigration may be restricted by limited external opportunities. Discrimination or lack of appropriate skills, for example, would reduce the value of migration. One way of assessing these factors would be to compare the characteristics of village residents with Natives who have migrated from the village.

\section{CONCLUSION}

In the introduction, we posed two questions about the remote regions research reviewed here: Has the research helped us to better understand how and why remote regions are different from other places? Has it given us a clearer view of remote regions' problems and what might be done about them? We conclude that the answer to both questions is a qualified yes.

Collectively, the remote regions papers have helped bring into focus a picture of regions, mostly within highly developed national states, that are remote physically, economically, and politically from their countries' centers of power and wealth. Associated with the characteristics of remoteness are a range of problems that resolve essentially into severe 
limits on these regions' political autonomy, economic self-sufficiency, and social welfare. We have also seen that the sources of these limits are internal as well as external to the region. Finally, we have begun to understand the difficulties involved in dealing with these limits in areas of resource development, Native claims, and village economies.

This review has also indicated research gaps, problem areas in which further research is especially needed, and ways in which remote regions research might be strengthened. The following summarizes our main recommendations.

First, remote regions research needs better theoretical frameworks, more original data gathering, and increased testing of hypotheses. These are essential requirements in any field of research, and they especially apply in a relatively new and largely unstructured area like remote regions research. To date, the research has been shaped largely by the problem and policy interests of the researchers, and this has helped to make their research purposeful and significant. In the future, more explicit theory and theorizing should provide a stronger research base for both prescriptive and non-prescriptive analysis.

Second, the research has been dominated by single-region case studies, and these have contributed valuable information and insight to the field. Because most of the participating researchers are based in Canada and Alaska, this work has concentrated on remote regions in those places. We need more studies focusing on the remote regions of such places as Scandanavia, Australia, and Micronesia. There are significant similarities, which provide the best basis for comparisons, as well as differences among these and other First World regions.

Third, historical studies have contributed much to our understanding of the processes and problems of remote regions. The field's research base can be strengthened by focusing increased attention on the origins, conduct, and results of development schemes for remote regions. This research should include efforts of private individuals and organizations as well as of governments, and it should attempt to identify and explain both successes and failures. 
Finally, while researchers in all disciplines should be concerned, anthropologists and economists in particular should take better account of each others' disciplinary viewpoints in their studies of village cultures and economies. Values, interests, and motivations at both community and individual levels are involved in the changes occurring in Native villages. Research frameworks need to accommodate both of these levels and focus more on the interactions of individual and communal factors. These are, after all, the kinds of interactions leading to adaptations that constitute culture change. 


\section{REFERENCES}

\section{WRSA-Remote Regions Papers}

Most of the WRSA papers listed below are unpublished. Interested readers should write directly to the authors for further information. Where published versions exist, we have added a citation.

Abele, F. 1985. Native Self-Determination and Practical Problems of Government. School of Public Administration, Carleton University, Ottawa.

Anders, G. and Anders, K. 1984. Incompatible Goals in Unconventional Organizations: The Politics of Alaska Native Corporations. Business Programs, Arizona State University, West Campus, P.O. Box 37100. Phoenix, AZ 85069-7100. (Published as Anders, G. and Anders, K. 1984. Incompatible Goals in Unconventional Organizations: The Politics of Alaska Native Corporations in T. Lane, ed. 1987. Developing America's Northern Frontier. Lanham: University Press of America.)

Ballendorf, D. 1990. Dependency and Decolonization in Micronesia. Micronesian Research Center, University of Guam, Mangilao.

Berman, M. 1986. Strategies for Economic Self-Reliance in Rural Northern Economies. Institute of Social and Economic Research, University of Alaska Anchorage. 1987. Development of the Northern Political Economy. 
1990. The Traditional Economy as the Employer of Last Resort.

Clark, B. and Coates, K. 1990. Indigenous Peoples in Peripheral Areas and Their Struggle for Land. Department of History, University of Victoria.

Coates, K. 1987. Limits to Growth: Problems in the Economic Development of the Yukon Territory, 1898-1986. University of Victoria, Department of History, P.O. Box 1700, Victoria, B.C., CANADA V8W 2Y2. (Published as Coates, K. 1987. The Federal Government and the Economic Develoment of the Yukon Territory: Historical and Contemporary Aspects of Northern Development in K. Coates and W. Morrison, eds. 1989. For Purposes of Dominion: Essays in Honour of Morris Zaslow. Toronto: Captus University Press.)

Cole, T. 1989. Golden Years: The Decline of Gold Mining in Alaska. Department of History, University of Alaska Fairbanks, Fairbanks, AK 99775. (Published as Cole, T. 1989. Golden Years: The Decline of Gold Mining in Alaska. Pacific Northwest Quarterly April 1989: 62.)

Copes, P. 1987. The Fishery as an Employer of Last Resort: A Failure of Regional Policy in Atlantic Canada. Institute of Fisheries Analysis, Simon Fraser University, Burnaby, B.C.

Dahl, J. 1988. Self-Government, Land Claims, and Imagined Inuit Communities. Institut for Eskimologi, Kobenhavns Universitet, Fiolstraede 10, DK-1171 Kobenhavin K, DENMARK. (Published as Dahl, J. 1988. Self-Government, Land Claims, and Imagined Inuit Communities. Kobenhavn: Folk Vol. 30.) 
Dubbs, P. 1988. Another Development in Alaska. Department of Rural Development, University of Alaska Fairbanks.

Goldsmith, 0. 1985. The Sustainability of the Alaska Economy. Institute of Social and Economic Research, University of Alaska Anchorage.

1987. Maximizing Benefits from Use of Depletable Resource Rents.

Harris, B. 1984. The Survival of Respect: Economic Power and Persistence of Community. Impact Assessment, Inc., 7453 High Avenue, La Jolla, CA 92037. (Published as Harris, B. 1984. The Survival of Respect: Economic Power and Persistence of Community in T. Lane, ed. 1987. Developing America's Northern Frontier. Lanham: University Press of America.)

Huskey, L. 1984. Import Substitution in Frontier Regions. Department of Economics, University of Alaska Anchorage, 3211 Providence Drive, Anchorage, AK 99508. (Published as Huskey, L. 1985. Import Substitution: The Hidden Dynamic in the Growth of Frontier Regions. Growth and Change 16(4):43-55.)

1986. Viable and Nonviable Market Communities in the North: Government Policy and Change.

- 1987. The Changing Parameters of Frontier Economic Development.

1989. Transfers, Mobility, and Poverty in Rural Alaska. 
Knapp, G. 1986. The Subsistence/Government/Transfer Economy: Questions for Public Policy. Institute of Social and Economic Research, University of Alaska Anchorage.

1987. Soviet Northern Development: Lessons for Alaska.

1990. An Economic Overview of the Soviet Far Northeast.

Knowler, D. 1989. Aspects of Absentee and Local Ownership of Industry in Remote Areas. Department of Economic Development, Government of Yukon.

_. 1990. Minerals Export in Remote Regions: A Case Study of Norbotten, Sweden, and Yukon, Canada.

Lane, T. and Thomas, C. 1984. The Labor Force Status of Alaska's Native Population. Institute of Social and Economic Research, University of Alaska Anchorage, 3211 Providence Drive, Anchorage, AK 99508. (Published as Lane, T. and Thomas, C. 1984. The Labor Force Status of Alaska's Native Population in T. Lane, ed. 1987. Developing America's Northern Frontier. Lanham: University Press of America.)

Langdon, S. 1984. Commercial Fisheries: Implications for Western Alaska Development. Department of Anthropology, University of Alaska Anchorage, 3211 Providence Drive, Anchorage, AK 99508. (Published as Langdon, S. 1984. Commercial Fisheries: Implications for Western Alaska Development in T. Lane, ed. 1987. Developing America's Northern Frontier. Lanham: University Press of America.) 
Lonner, T. 1985. Incipient Governance Among Alaska Native Peoples. Alaska State Museum, Juneau.

Lyck, L. 1990. Circumpolar Development: A Comparative Analysis. Institute of Economics, University of Copenhagen.

Morehouse, T. 1986. Political Development in the North. Institute of Social and Economic Research, University of Alaska Anchorage, 3211 Providence Drive, Anchorage, AK 99508. (Published as Morehouse, T. 1987. The Meaning of Political Development in the North. Polar Record 23(145):405-410).

1987. Comparative Native Claims and Political Development. Institute of Social and Economic Research, University of Alaska Anchorage, 3211 Providence Drive, Anchorage, AK 99508. (Published as Morehouse, T. 1987. Native Claims and Political Development. ISER Occasional Papers 18.)

. 1988. The Alaska Native Claims Settlement Act and Tribal Government. Institute of Social and Economic Research, University of Alaska Anchorage, 3211 Providence Drive, Anchorage, AK 99508. (Published as Morehouse, T. 1988. The Alaska Native Claims Settlement Act, 1991, and Tribal Government. ISER Occasional Papers 19.)

1989. Alaska Native Political Economy. Institute of Social and Economic Research, University of Alaska Anchorage, 3211 Providence Drive, Anchorage, AK 99508. (Published as Morehouse, T. 1989. Rebuilding the Political Economies of Alaska Native Villages. ISER Occasional Papers 21.) 
Morrison, W. 1987. The Comprehensive Claims Process in Canada's North: New Rhetoric, Old Policies. Center for Northern Studies, Lakehead University, Thunder Bay, Ontario, CANADA P7B 5E1. (Published as Morrison, W. 1987. The Comprehensive Claims Process in Canada's North: New Rhetoric, Old Policies in K. Coates and W. Morrison, eds. 1989. For Purposes of Dominion: Essays in Honour of Morris Zaslow. Toronto: Captus University Press.)

Morse, B. 1985. Indigenous Self-Government in Canada. Faculty of Law, University of Ottawa.

Naske, C. 1987. A Federal Effort to Provide Territorial Alaska with an Economic Base. Department of History, University of Alaska Fairbanks.

Nord, D. 1990. Creating Political Institutions for the Periphery: Comparative Perspectives. Institute for International Studies, University of Minnesota, Duluth.

Osherenko, G. 1988. Wildlife Management in the North American Arctic: The Case for Co-Management. The Center for Northern Studies, Wolcott, Vermont.

Petterson, J. 1984. Subsistence Continuity and Economic Abundance in the North. Impact Assessment, Inc., 7453 High Avenue, La Jolla, CA 92037. (Published as Petterson, J. 1984. Subsistence Continuity and Economic Abundance in the North in T. Lane, ed. 1987. Developing America's Northern Frontier. Lanham: University Press of America.)

Pretes, M. 1988. Patterns of Development in Two Norths: Underdevelopment in the Brazilian Amazon and the Canadian Arctic. The Arctic Institute of North America, University of Calgary, 
2550 University Dr., N.W., Calgary, Alberta, CANADA T2N 1N4. (Published as Pretes, M. 1988. Underdevelopment in Two Norths: The Brazilian Amazon and the Canadian Arctic. Arctic $41(2): 109-116$.

and Robinson, M. 1989. Beyond Boom and Bust: A Strategy for Creating Sustainable Development in the North. The Arctic Institute of North America, University of Calgary, 2550 University Dr., N.W., Calgary, Alberta, CANADA T2N 1N4. (Published as Pretes, M and Robinson, M. 1989. Beyond Boom and Bust: A Strategy for Sustainable Development in the North. Polar Record 25(153): 115-120.)

Saarinen, 0. 1989. Downsizing Towards the Sustainable Community: The Sudbury Study. Department of Geography, Laurentian University, Sudbury, Ontario, CANADA P3E 2 L6. (Published as Saarinen, O. 1990. Sudbury: A Historical Case Study of Multiple UrbanEconomic Transformation. Ontario History LXXXII(1).)

Sager, E. 1988. Dependency, Underdevelopment, and the Economic History of the Atlantic Provinces of Canada. Department of History, University of Victoria, P.O. Box 1700, Victoria, B.C., CANADA V8W 2Y2. (Published as Sager, E. 1987. Dependency, Underdevelopment, and the Economic History of the Atlantic Provinces. Acadiensis XVII(1):117-137.)

Shrimpton, M. and Storey, K. 1989. The Urban Miner: Long Distance Commuting to Work in the Mining Sector and Its Implications for the Canadian North. Department of Geography, Memorial University of Newfoundland, St. John's, Newfoundland, CANADA A1B $3 \times 9$. (Published as Shrimpton, M. and Storey, K. 1989. The Urban Miner: Long Distance Commuting to Work in the Mining Sector and Its Implications for the Canadian North in R. 
Robson, ed. 1988. The Commuting Alternative: A Contemporary Response to Community Needs in the Resource Sector, Northern Studies 1.)

Sinclair, W. 1985. Native Self-Reliance through Resource Management. Environment Canada, 1250 Ottaburn Avenue, West Vancouver, B.C., CANADA V7S 2J8. (Published as Sinclair, W. 1985. Native Self-Reliance through Resource Development. Proceedings of International Conference "Towards Native Self-Reliance Renewal and Development," Vancouver, Canada, August $19-24,1984$.

Stabler, J. 1987. The Northern Labor Force and Dualism. Department of Economics, University of Saskatchewan, Saskatoon, Saskatchewan, CANADA S7N OWO. (Published as Stabler, J. 1989. Dualism and Development in the Northwest Territories. Economic Development and Cultural Change 37(4).)

1988. The Role of the Traditional Sector in the Economy of the Northwest Territories: Preferred Vocation or Employer of Last Resort? Department of Economics, University of Saskatchewan, Saskatoon, Saskatchewan, CANADA S7N OWO. (Published as Stabler, J. 1990. A Utility Analysis of Activity Patterns of Native Males in the Northwest Territories. Economic Development and Cultural Change 39(1):47-62.)

1989. Fur Trappers in the Northwest Territories: An Econometric Analysis of the Factors Influencing Participation. Department of Economics, University of Saskatchewan, Saskatoon, Saskatchewan, CANADA S7N OWO. (Published as Stabler, J. 1990. Fur Trappers in the Northwest Territories: An Econometric Analysis of the Factors Influencing Participation. Arctic 43(1):1-8.) 
and Howe, E. 1990. Socio-Economic Transformation of the Native People of the Northwest Territories, 1800-2000.

Taylor, J. 1988. Rapid Urban Development and Aboriginal Population Mobility in Australia's Northern Territory. Northern Australia Research Unit, The Australian National University, P.O. Box 41321, Casuarina, NT AUSTRALIA 5792. (Published as Taylor, J. 1989. Public Policy and Aboriginal Population Mobility: Insights from the Katherine Region, Northern Territory. Australian Geographer 20(1):47.)

Tuck, B. 1984. Structural Change in Alaska: The Impact of the Petroleum Industry. Department of Economics, University of Alaska Anchorage.

Weller, G. 1990. The Devolution of Authority for Health Care Services to the Government of the Northwest Territories. University of Northern British Columbia.

\section{Other Works Cited}

Knapp, G. 1988. The Economic Outlook for Rural Alaska. Institute of Social and Economic Research, University of Alaska Anchorage.

and Huskey, L. 1988. Effects of Transfers on Remote Regional Economies: The Transfer Economy in Rural Alaska. Growth and Change, Vol. 19, No. 2, Spring. 
Leven, C. 1986. A Note on the Economics of Remoteness. Regional Dynamics of Socio-economic Change: Experiences and Prospects in Sparsely Settled Areas. E. Bylund and U. Wyberg, eds. Umea, Sweden: CERUM.

So, A. 1990. Social Change and Development: Modernization, Dependency, and World-System Theories. Newbury Park, CA: Sage Publications, Inc.

Staniland, M. 1985. What is Political Economy? A Study of Social Theory and Undervelopment. New Haven: Yale University Press.

Usher, P. 1987. Indigenous Management Systems and the Conservation of Wildlife in the Canadian North. Alternatives. Vol. 14, February.

Wallerstein, I. 1974. The Modern World-System. New York: Academic Press. 1979. The Capitalist World-Economy. Cambridge: Cambridge University Press.

Watkins, M. 1972. A Staple Theory of Economic Growth. Readings in Economic Development. Cincinnati: South-Western Publishing Co. 